\title{
Data Mining in Healthcare: Applying Strategic Intelligence Techniques to Depict 25 Years of Research Development
}

\author{
Maikel Luis Kolling ${ }^{1}$, Leonardo B. Furstenau ${ }^{2} \mathbb{D}$, Michele Kremer Sott ${ }^{1} \mathbb{D}$, Bruna Rabaioli ${ }^{3} \mathbb{D}$, \\ Pedro Henrique Ulmi ${ }^{4}$, Nicola Luigi Bragazzi ${ }^{5, *(D)}$ and Leonel Pablo Carvalho Tedesco $1,4, *$ (D) \\ 1 Graduate Program of Industrial Systems and Processes, University of Santa Cruz do Sul, \\ Santa Cruz do Sul 96816-501, Brazil; maikel.kolling@gmail.com (M.L.K.); sott.mk@gmail.com (M.K.S.) \\ 2 Department of Industrial Engineering, Federal University of Rio Grande do Sul, \\ Porto Alegre 90035-190, Brazil; leonardofurstenau@mx2.unisc.br \\ 3 Department of Medicine, University of Santa Cruz do Sul, Santa Cruz do Sul 96816-501, Brazil; \\ brunarabbaioli@gmail.com \\ 4 Department of Computer Science, University of Santa Cruz do Sul, Santa Cruz do Sul 96816-501, Brazil; \\ pedroh.u@hotmail.com \\ 5 Laboratory for Industrial and Applied Mathematics (LIAM), Department of Mathematics and Statistics, \\ York University, Toronto, ON M3J 1P3, Canada \\ * Correspondence: robertobragazzi@gmail.com (N.L.B.); leoneltedesco@unisc.br (L.P.C.T.)
}

check for updates

Citation: Kolling, M.L.; Furstenau, L.B.; Sott, M.K.; Rabaioli, B.; Ulmi, P.H.; Bragazzi, N.L.; Tedesco, L.P.C. Data Mining in Healthcare: Applying Strategic Intelligence Techniques to Depict 25 Years of Research Development. Int. J. Environ. Res. Public Health 2021, 18, 3099. https:// doi.org/10.3390/ijerph18063099

Academic Editor: Paul B. Tchounwou

Received: 29 January 2021

Accepted: 15 March 2021

Published: 17 March 2021

Publisher's Note: MDPI stays neutral with regard to jurisdictional claims in published maps and institutional affiliations.

Copyright: (c) 2021 by the authors. Licensee MDPI, Basel, Switzerland. This article is an open access article distributed under the terms and conditions of the Creative Commons Attribution (CC BY) license (https:// creativecommons.org/licenses/by/ $4.0 /)$

\begin{abstract}
In order to identify the strategic topics and the thematic evolution structure of data mining applied to healthcare, in this paper, a bibliometric performance and network analysis (BPNA) was conducted. For this purpose, 6138 articles were sourced from the Web of Science covering the period from 1995 to July 2020 and the SciMAT software was used. Our results present a strategic diagram composed of 19 themes, of which the 8 motor themes ('NEURAL-NETWORKS', 'CANCER', 'ELETRONIC-HEALTH-RECORDS', 'DIABETES-MELLITUS', 'ALZHEIMER'S-DISEASE', 'BREASTCANCER', 'DEPRESSION', and 'RANDOM-FOREST') are depicted in a thematic network. An indepth analysis was carried out in order to find hidden patterns and to provide a general perspective of the field. The thematic network structure is arranged thusly that its subjects are organized into two different areas, (i) practices and techniques related to data mining in healthcare, and (ii) health concepts and disease supported by data mining, embodying, respectively, the hotspots related to the data mining and medical scopes, hence demonstrating the field's evolution over time. Such results make it possible to form the basis for future research and facilitate decision-making by researchers and practitioners, institutions, and governments interested in data mining in healthcare.
\end{abstract}

Keywords: data mining; industry 4.0; healthcare 4.0; bibliometrics; science mapping; strategic intelligence; co-word analysis; SciMAT

\section{Introduction}

Deriving from Industry 4.0 that pursues the expansion of its autonomy and efficiency through data-driven automatization and artificial intelligence employing cyber-physical spaces, the Healthcare 4.0 portrays the overhaul of medical business models towards a data-driven management [1]. In akin environments, substantial amounts of information associated to organizational processes and patient care are generated. Furthermore, the maturation of state-of-the-art technologies, namely, wearable devices, which are likely to transform the whole industry through more personalized and proactive treatments, will lead to a noteworthy increase in user patient data. Moreover, the forecast for the annual global growth in healthcare data should exceed soon 1.2 exabytes a year [1]. Despite the massive and growing volume of health and patient care information [2], it is still, to a great extent, underused [3].

Data mining, a subfield of artificial intelligence that makes use of vast amounts of data in order to allow significant information to be extracted through previously unknown pat- 
terns, has been progressively applied in healthcare to assist clinical diagnoses and disease predictions [2]. This information has been known to be rather complex and difficult to analyze. Furthermore, data mining concepts can also perform the analysis and classification of colossal bulks of information, grouping variables with similar behaviors, foreseeing future events, amid other advantages for monitoring and managing health systems ceaselessly seeking to look after the patients' privacy [4]. The knowledge resulting from the application of the aforesaid methods may potentially improve resource management and patient care systems, assist in infection control and risk stratification [5]. Several studies in healthcare have explored data mining techniques to predict incidence [6] and characteristics of patients in pandemic scenarios [7], identification of depressive symptoms [8], prediction of diabetes [9], cancer [10], scenarios in emergency departments [11], amidst others. Thus, the utilization of data mining in health organizations ameliorates the efficiency of service provision [12], quality of decision making, and reduces human subjectivity and errors [13].

The understanding of data mining in the healthcare sector is, in this context, vital and some researchers have executed bibliometric analyses in the field with the intention of investigating the challenges, limitations, novel opportunities, and trends [14-17]. However, at the time of this study, there were no published works that provided a complete analysis of the field using a bibliometric performance and network analysis (BPNA) (see Table 1. In the light of this, we have defined three research questions:

RQ1: What are the strategic themes of data mining in healthcare?

RQ2: How is the thematic evolution structure of data mining in healthcare?

RQ3: What are the trends and opportunities of data mining in healthcare for academics and practitioners?

Table 1. Existing bibliometric analysis of data mining in healthcare in Web of Science (WoS).

\begin{tabular}{ccc}
\hline Study & Coverage & Focus \\
\hline$[14]$ & $2000-2017$ & $\begin{array}{c}\text { Analysis of the evolution of emerging technologies (e.g., } \\
\text { data mining, machine learning, among others) in cancer } \\
\text { using CiteSpace software. }\end{array}$ \\
\hline$[15]$ & $2009-2018$ & $\begin{array}{c}\text { Exploration of data mining and machine learning in } \\
\text { public health sector. }\end{array}$ \\
\hline T16] & $2011-2019$ & $\begin{array}{c}\text { Investigation of medical data mining using VOSviewer } \\
\text { and CiteSpace software. }\end{array}$ \\
\hline This paper & $1995-2020$ & $\begin{array}{c}\text { A BPNA of data mining in healthcare: performance } \\
\text { analysis, strategic themes, thematic evolution structure, } \\
\text { trends and future opportunities using SciMAT software. }\end{array}$ \\
\hline
\end{tabular}

Thus, with the objective to lay out a superior understanding of the data mining usage in the healthcare sector and to answer the defined research questions, we have performed a bibliometric performance and network analysis (BPNA) to set fourth an overview of the area. We used the Science Mapping Analysis Software Tool (SciMAT), a software developed by Cobo et al. [18] with the purpose of identifying strategic themes and the thematic evolution structure of a given field, which can be used as a strategic intelligence tool. The strategic intelligence, an approach that can enhance decision-making in terms of science and technology trends [19-27], can help researchers and practitioners to understand the area and devise new ideas for future works as well as to identify the trends and opportunities of data mining in healthcare.

This research is structured as follows: Section 2 highlights the methodology and the dataset. Section 3 presents the bibliometric performance of data mining in healthcare. In Section 4, the strategic diagram presents the most relevant themes according to our bibliometric indicators as well as the thematic network structure of the motor themes and the thematic evolution structure, which provide a complete overview of data mining over time. Section 5 presents the conclusions, limitations, and suggestions for future works. 


\section{Methodology and Dataset}

Attracting attention from companies, universities, and scientific journals, bibliometric analysis enhances decision-making by providing a reliable method to collect information from databases, to transform the aforementioned data into knowledge, and to stimulate wisdom development. Furthermore, the techniques of bibliometric analysis can provide higher and different perspectives of scientific production by using advanced measurement tools and methods to depict how authors, works, journals and institutions are advancing in a specific field of research through the hidden patterns that are embedded in large datasets.

The existing works on bibliometric analysis of data mining in health care in the Web of Science are shown in Table 1, where it is depicted that only three studies have been performed and the differences between these approaches and this work are explained.

\subsection{Methodology}

For this study we have applied BPNA, a method that combines science mapping with performance analysis, to the field of data mining in healthcare with the support of the SciMAT software. This methodology has been chosen in view of the fact that such a combination, in addition to assisting decision-making for academics and practitioners, allows us to perform a deep investigation into the field of research by giving a new perspective of its intricacies. The BPNA conducted in this paper was composed of four steps outlined below.

\subsubsection{Discovery of Research Themes}

The themes were identified using a frequency and network reduction of keywords. In this process, the keywords were firstly normalized using the Salton's Cosine, a correlation coefficient, and then clustered through the simple center algorithm. Finally, the thematic evolution structure co-word network was normalized using the equivalence index.

\subsubsection{Depicting Research Themes}

The previously identified themes were then plotted on a bi-dimensional diagram composed of four quadrants, in which the "vertical axis" characterizes the density (D) and the "horizontal axis" characterizes the centrality (C) of the theme $[28,29]$ (Figure 1a) [18,20,25,30-33].

(a) First quadrant-motor themes: trending themes for the field of research with high development.

(b) Second quadrant-basic and transversal themes: themes that are inclined to become motor themes in the future due to their high centrality.

(c) Third quadrant-emerging or declining themes: themes that require a qualitative analysis to define whether they are emerging or declining.

(d) Fourth quadrant-highly developed and isolated themes: themes that are no longer trending due to a new concept or technology.

\subsubsection{Thematic Network Structure and Detection of Thematic Areas}

The results were organized and structured in (a) a strategic diagram (b) a thematic network structure of motor themes, and (c) a thematic evolution structure. The thematic network structure (Figure 1b) represents the co-occurrence between the research themes and underlines the number of relationships (C) and internal strength among them (D). The thematic evolution structure (Figure 1c) provides a proper picture of how the themes preserve a conceptual nexus throughout the following sub-periods [23,34]. The size of the clusters is proportional to the number of core documents and the links indicate cooccurrence among the clusters. Solid lines indicate that clusters share the main theme, and dashed lines represent the shared cluster elements that are not the name of the themes [35]. The thickness of the lines is proportional to the inclusion index, which indicates that the themes have elements in common [35]. Furthermore, in the thematic network structure 
the themes were then manually classified between data mining techniques and medical research concepts.

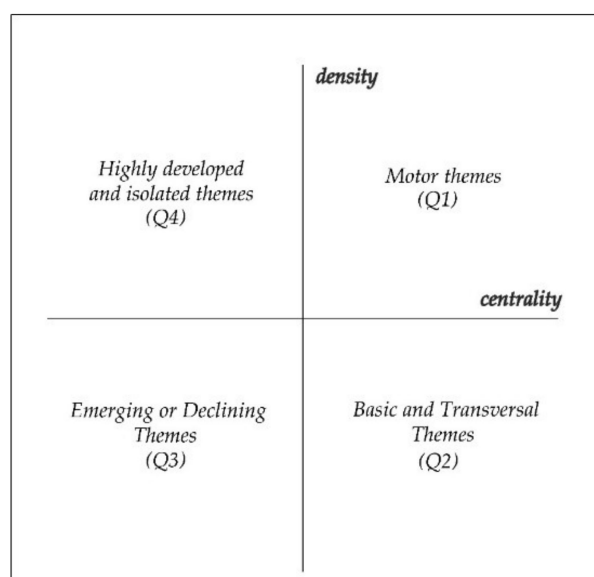

(a)

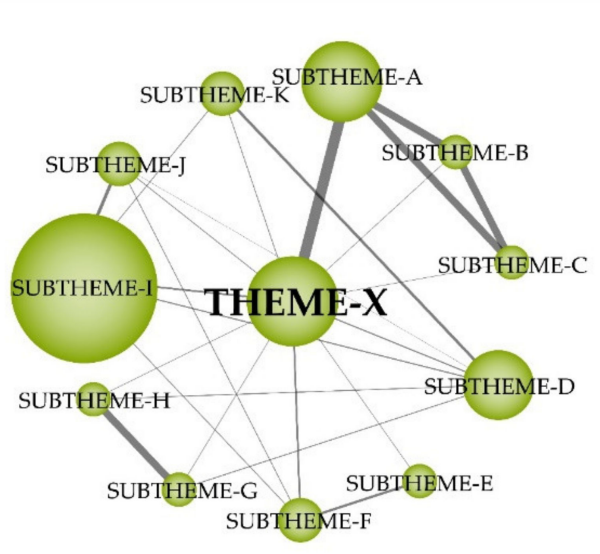

(b)

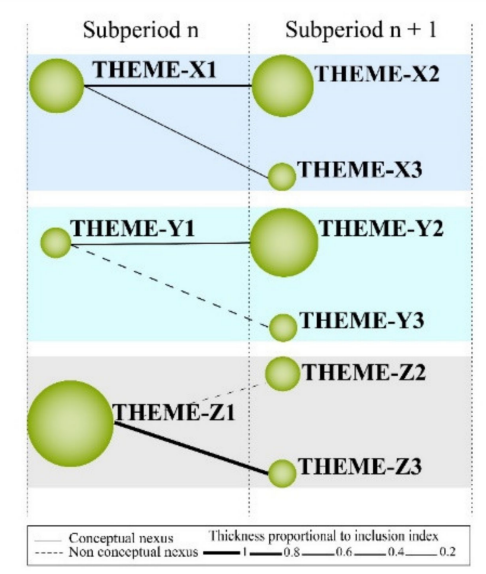

(c)

Figure 1. Strategic diagram (a). Thematic network structure (b). Thematic evolution structure (c).

\subsubsection{Performance Analysis}

The scientific contribution was measured by analyzing the most important research themes and thematic areas using the h-index, sum of citations, core documents centrality, density, and nexus among themes. The results can be used as a strategic intelligence approach to identify the most relevant topics in the research field.

\subsection{Dataset}

Composed of 6138 non-duplicated articles and reviews in English language, the dataset used in this work was sourced from the Web of Science (WoS) database utilizing the following query string ("data mining" and ("health" OR "clinic" OR "medic* OR "disease")). The documents were then processed and had their keywords, both the author's and the index controlled and uncontrolled terms, extracted and grouped in accordance with their meaning. In order to remove duplicates and terms which had less than two occurrences in the documents, a preprocessing step was applied to the authors, years, publication dates, and keywords. For instance, the preprocessing has reduced the total number of keywords from 21,838 to 5310, thus improving the bibliometric analysis clarity. With the exception of the strategic diagram that was plotted utilizing a single period (1995-July 2020), in this study, the timeline was divided into three sub-periods: 1995-2003, 2004-2012, and 2013-July 2020.

Subsequently, a network reduction was applied in order to exclude irrelevant words and co-occurrences. For the network extraction we wanted to identify co-occurrence among words. For the mapping process, we used a simple center algorithm. Finally, a core mapper was used, and the h-index and sum citations were selected. Figure 2 shows a good representation of the steps of the BPNA. 


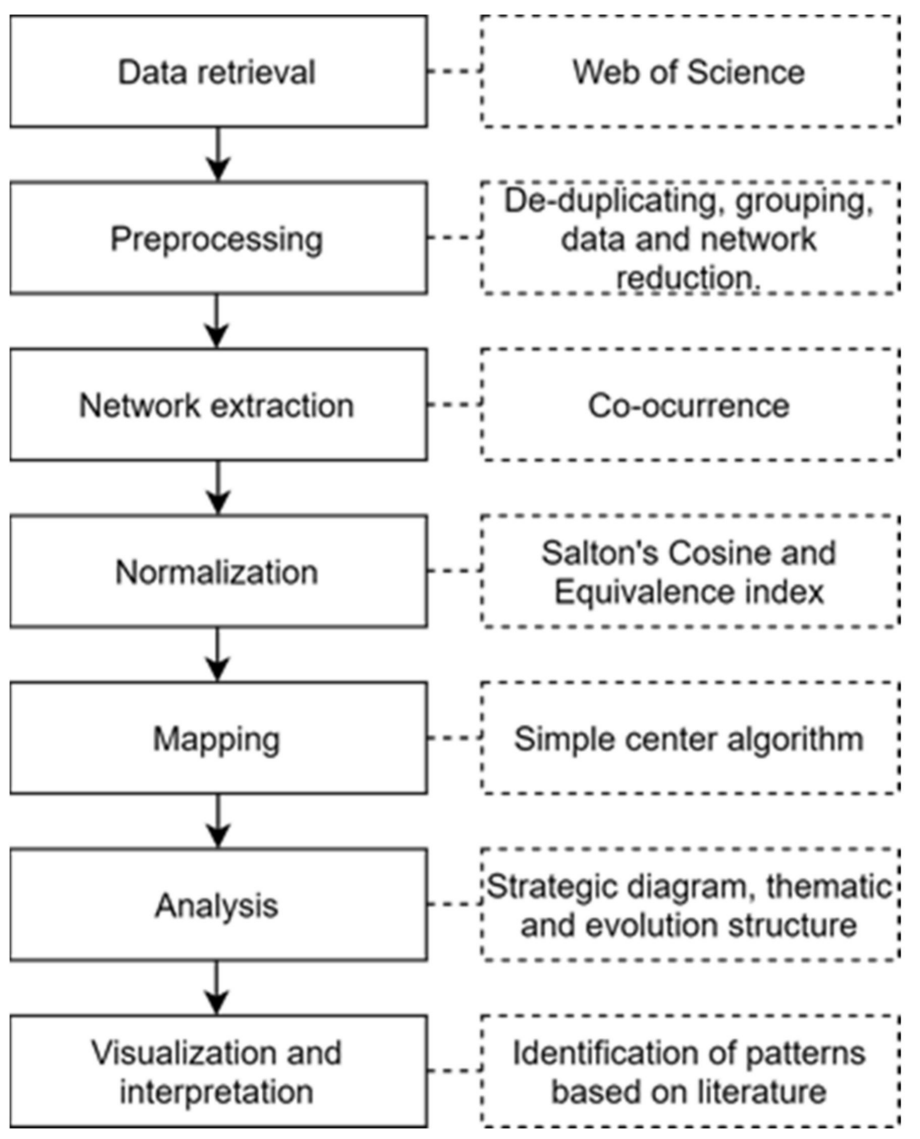

Figure 2. Workflow of the bibliometric performance and network analysis (BPNA).

\section{Bibliometric Performance of Data Mining in Healthcare}

In this section, we measured the performance of the field of data mining in healthcare in terms of publications and citations over time, the most productive and cited researchers, as well as productivity of scientific journals, institutions, countries, and most important research areas in the WoS. To do this, we used indicators such as: number of publications, sum of citations by year, journal impact factor (JIF), geographic distribution of publications, and research field. For this, we examined the complete period (1995 to July 2020).

\subsection{Publications and Citations Overtime}

Figure 3 shows the performance analysis of publications and citations of data mining in healthcare over time from 1995 to July 2020 in the WoS. The first sub-period (1995-2003) shows the beginning of the research field with 316 documents and a total of 13,483 citations. Besides, the first article in the WoS was published by Szolovits (1995) [36] who presented a tutorial for handling uncertainty in healthcare and highlighted the importance to develop data mining techniques in order to assist the healthcare sector. This sub-period shows a slightly increasing number of citations until 2003 and the year with the highest number of citations was 2002.

The slightly increasing number continues from the first sub-period to the second subperiod (2004-2013) with a total of 1572 publications and 55,734 citations. The year 2006 presents the highest number of citations mainly due to the study of Fawcett [37] which attracted 7762 citations. The author introduced the concept of Receiver Operating Characteristics (ROC). This technique is widely used in data mining to assist medical decision-making. 


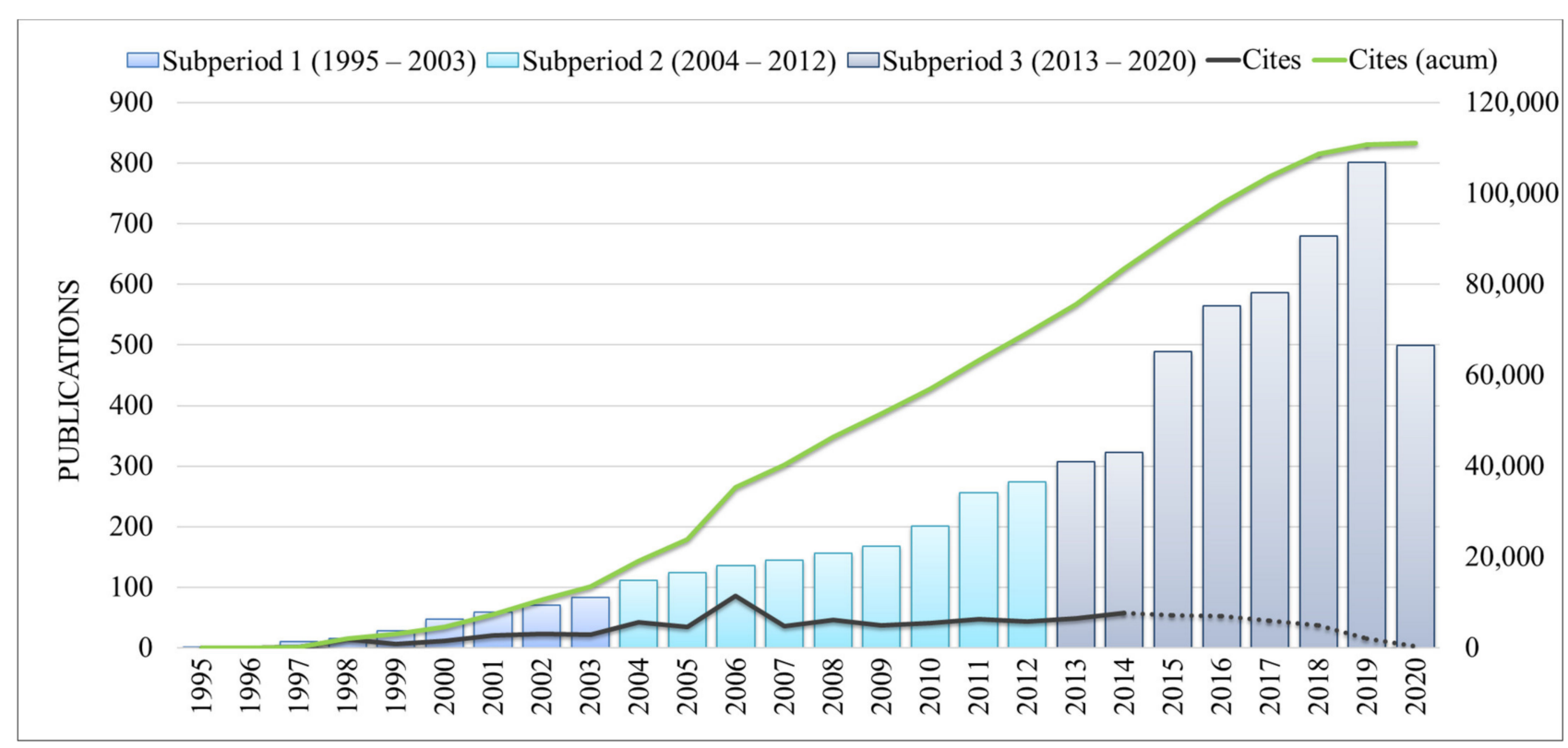

Figure 3. Number of publications over time (1995-July 2020).

From the second to the third sub-period, it is possible to observe a huge increase in the number of publications (4250 publications) and 41,821 citations. This elevated increase may have occurred due to the creation of strategies to implement emerging technologies in the healthcare sector in order to move forward with the third digital revolution in healthcare, the so-called Healthcare $4.0[1,38]$. Furthermore, although the citations are showing a positive trend, it is still possible to observe a downward trend from 2014 to 2020. This may happen, as Wang [39] highlights, due to the fact that a scientific document needs three to seven years to reach its peak point of citation [34]. Therefore, this is not a real trend.

\subsection{Most Productive and Cited Authors}

Table 2 displays the most productive and cited authors from 1995 to July 2020 of data mining in healthcare in the WoS. Leading as the most productive researcher in the field of data mining in healthcare is $\mathrm{Li}$, Chien-Feng, a pathologist at Chi Mei Hospital which is sixth-ranked in publication numbers. He dedicates his studies to the molecular diagnosis of cancer with innovative technologies. In the sequence, Acharya, U. Rajendra, ranked in the top $1 \%$ of highly cited researchers in five consecutive years $(2016,2017,2018,2019$, and 2020) in computer science according to Thomson's essential science indicators, shares second place with Chung, Kyungyong from the Division of Engineering and Computer Science at the Kyonggi University in Su-won-si, South Korea. On the other hand, Bate, Andrew C., a member of the Food and Drug Administration (FDA) Science Council of Pharmacovigilance Subcommittee, which is the fourth-ranked institution in publication count as the most cited researcher with 945 citations. Subsequently, Lindquist, Marie, who monitors global pharmacovigilance and data management development at the World Health Organization (WHO), is ranked second with 943 citations. Last but not least, Edwards, E.R., an orthopedic surgeon at the Royal Australasian College of Surgeons is ranked third with 888 citations. Notably, this study does not demonstrate a direct correlation between the number of publications and the number of citations.

\subsection{Productivity of Scientific Journals, Universities, Countries and Most Important Research Fields}

Table 3 shows the journals that publish studies related to data mining in healthcare. PLOS One is the first ranked with 124 publications, followed by Expert Systems with Applications with 105, and Artificial Intelligence in Medicine with 75. On the other hand, 
the journal Expert Systems with Applications is the journal that had the highest Journal Impact Factor (JIF) from 2019-2020.

Table 2. Most Cited/Productive authors from 1995 to July 2020.

\begin{tabular}{cccc}
\hline Author Citation & Citations & Author Productivity & Documents \\
\hline Bate, Andrew C. & 945 & Li, Chien-Feng & 36 \\
Lindquist, Marie & 943 & Acharya, U. Rajendra & 21 \\
Edwards, E.R. & 888 & Chung, Kyungyong & 21 \\
Moore, Jason H. & 711 & Chen, Gang & 19 \\
Cook, Diane, J. & 599 & Lee, Sung-Wei & 18 \\
Eppig, Janan, T. & 577 & Moore, Jason H. & 17 \\
White, Bill, C. & 541 & Cano, Maria & 17 \\
Bellazi, Riccardo & 527 & Chang, I-Wei & 16 \\
Szarfman, A. & 511 & He, Hong-Lin & 16 \\
Lambin, Philippe & 489 & Moro, Pedro L. & 16 \\
\hline
\end{tabular}

Table 3. Journals that publish studies to data mining in healthcare.

\begin{tabular}{ccc}
\hline Journal & Doc. & JIF \\
\hline PLOS One & 124 & 2.74 \\
Expert Systems with Applications & 105 & 5.89 \\
Artificial Intelligence in Medicine & 75 & 4.47 \\
Journal of Biomedical Informatics & 75 & 3.57 \\
BMC Bioinformatics & 66 & 2.13 \\
Journal of Medical Systems & 65 & 2.83 \\
IEEE Access & 65 & 3.74 \\
Computer Methods and Programs in Biomedicine & 59 & 3.63 \\
International Journal of Advanced Computer Science and Applications & 54 & 1.32 \\
Journal of The American Medical Informatics Association & 53 & 4.11 \\
\hline
\end{tabular}

Table 4 shows the most productive institutions and the most productive countries. The first ranked is Columbia University followed by U.S. FDA Registration and Harvard University. In terms of country productivity, United States is the first in the rank, followed by China and England. In comparison with Table 2, it is possible to notice that the most productive author is not related to the most productive institutions (Columbia University and U.S. FDA Registration). Besides, the institution with the highest number of publications is in the United States, which is found to be the most productive country.

Table 4. Institutions and countries that publish studies to data mining in healthcare.

\begin{tabular}{cccc}
\hline University & Documents & Country & Documents \\
\hline Columbia University & 62 & United States & 1973 \\
U.S. FDA Registration & 62 & China & 923 \\
Harvard University & 60 & England & 370 \\
Stanford University & 55 & India & 354 \\
Chinese Academy of Sciences & 53 & Germany & 312 \\
Chi Mei Medical Center & 47 & Italy & 297 \\
University of Pennsylvania & 45 & Taiwan & 294 \\
Kaohsiung Medical University & 44 & Australia & 282 \\
University of Toronto & 44 & Canada & 252 \\
University of Pittsburgh & 44 & Netherlands & 117 \\
\hline
\end{tabular}

Regarding Columbia University, it is possible to verify its prominence in data mining in healthcare through its advanced data science programs, which are one of the best evaluated and advanced in the world. We highlight the Columbia Data Science Society, 
an interdisciplinary society that promotes data science at Columbia University and the New York City community.

The U.S. FDA Registration has a data mining council to promote the prioritization and governance of data mining initiatives within the Center for Biological Research and Evaluation to assess spontaneous reports of adverse events after the administration of regulated medical products. In addition, they created an Advanced and Standards-Based Network Analyzer for Clinical Assessment and Evaluation (PANACEA), which supports the application of standards recognition and network analysis for reporting these adverse events. It is noteworthy that the FDA Adverse Events Reporting System (FAERS) database is the main resource that identifies adverse reactions in medications marketed in the United States. A text mining system based on EHR that retrieves important clinical and temporal information is also highlighted along with support for the Cancer Prevention and Control Division at the Centers for Disease Control and Prevention in a big data project.

The Harvard University offers online data mining courses and has a Center for Healthcare Data Analytics created by the need to analyze data in large public or private data sets. Harvard research includes funding and providing healthcare, quality of care, studies on special and disadvantaged populations, and access to care.

Table 5 presents the most important WoS subject research fields of data mining in healthcare from 1995 to July 2020. Computer Science Artificial Intelligence is the first ranked with 768 documents, followed by Medical Informatics with 744 documents, and Computer Science Information Systems with 722 documents.

Table 5. Most relevant WoS subject categories and research fields.

\begin{tabular}{cc}
\hline WoS Subject Categories & Doc. \\
\hline Computer Science Artificial Intelligence & 768 \\
Medical Informatics & 744 \\
Computer Science Information Systems & 722 \\
Computer Science Interdisciplinary Applications & 603 \\
Mathematical Computational Biology & 505 \\
Health Care Sciences Services & 419 \\
Pharmacology Pharmacy & 370 \\
Engineering Electrical Electronic & 364 \\
Computer Science Theory Methods & 357 \\
Biochemical Research Methods & 304 \\
\hline
\end{tabular}

\section{Science Mapping Analysis of Data Mining in Healthcare}

In this section the science mapping analysis of data mining in healthcare is depicted. The strategic diagram shows the most relevant themes in terms of centrality and density. The thematic network structure uncovers the relationship (co-occurrence) between themes and hidden patterns. Lastly, the thematic evolution structure underlines the most important themes of each sub-period and shows how the field of study is evolving over time.

\subsection{Strategic Diagram Analysis}

Figure 4 presents 19 clusters, 8 of which are categorized as motor themes ('NEURALNETWORKS', 'CANCER', 'ELETRONIC-HEALTH-RECORDS', 'DIABETES-MELLITUS', 'ADVERSE-DRUG-EVENTS', 'BREAST-CANCER', 'DEPRESSION' and 'RANDOM-FOREST'), 2 as basic and transversal themes ('CORONARY-ARTERY-DISEASE' and 'PHOSPHORYLATION'), 7 as emerging or declining themes ('PERSONALIZED-MEDICINE', 'DATAINTEGRATION', 'INTENSIVE-CARE-UNIT', 'CLUSTER-ANALYSIS', 'INFORMATIONEXTRACTION', 'CLOUD-COMPUTING' and 'SENSORS'), and 2 as highly developed and isolated themes ('ALZHEIMERS-DISEASE', and 'METABOLOMICS'). 


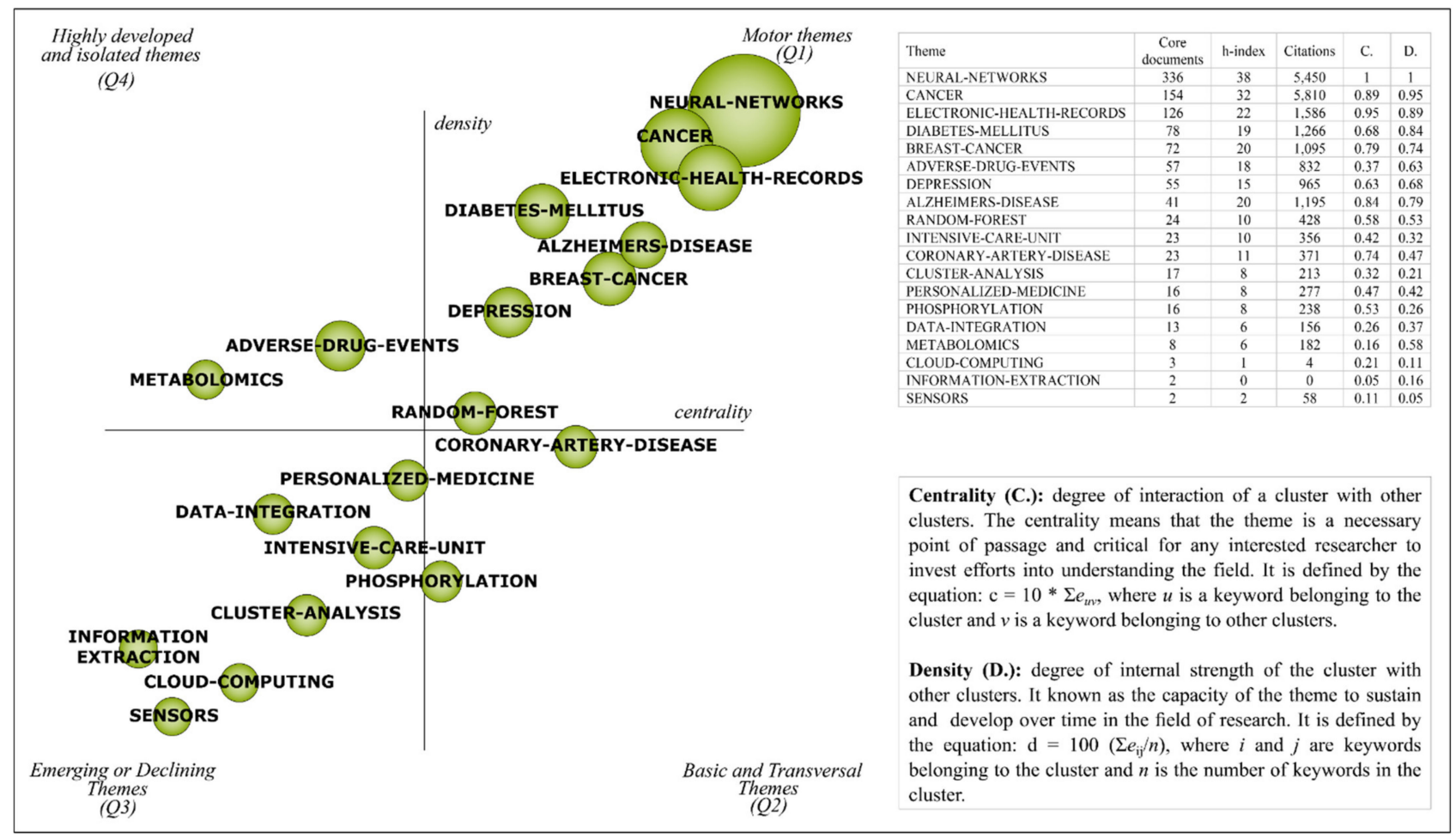

Figure 4. Strategic diagram of data mining in healthcare (1995-July 2020).

Each cluster of themes was measured in terms of core documents, h-index, citations, centrality, and density. The cluster 'NEURAL-NETWORKS' has the highest number of core documents (336) and is ranked first in terms of centrality and density. On the other hand, the cluster 'CANCER' is the most widely cited with 5810 citations.

\subsection{Thematic Network Structure Analysis of Motor Themes}

The motor themes have an important role regarding the shape and future of the research field because they correspond to the key topics to everyone interested in the subject. Therefore, they can be considered as strategic themes in order to develop the field of data mining in healthcare. The eight motor themes are discussed below, and they are displayed below in Figure 5 together with the network structure of each theme.

\subsubsection{Neural Network (a)}

The cluster 'NEURAL-NETWORKS' (Figure 5a) is the first ranked in terms of core documents, h-index, centrality, and density. The 'NEURAL-NETWORKS' cluster is strongly influenced by subthemes related to data science algorithms, such as 'SUPPORT-VECTORMACHINE', 'DECISION-TREE', among others. This network represents the use of data mining techniques to detect patterns and find important information correlated to patient health and medical diagnosis. A reasonable explanation for this network might be related to the high number of studies which conducted benchmarking of neural networks with other techniques to evaluate performance (e.g., resource usage, efficiency, accuracy, scalability, etc.) [40-42]. Besides, the significant size of the cluster 'MACHINE-LEARNING' is expected since neural networks is a type of machine learning. On the other hand, the subtheme 'HEART-DISEASE' stands out as the single disease in this network, which can be justified by the high number of researches with the goal to apply data mining to support decisionmaking in heart disease treatment and diagnosis. 

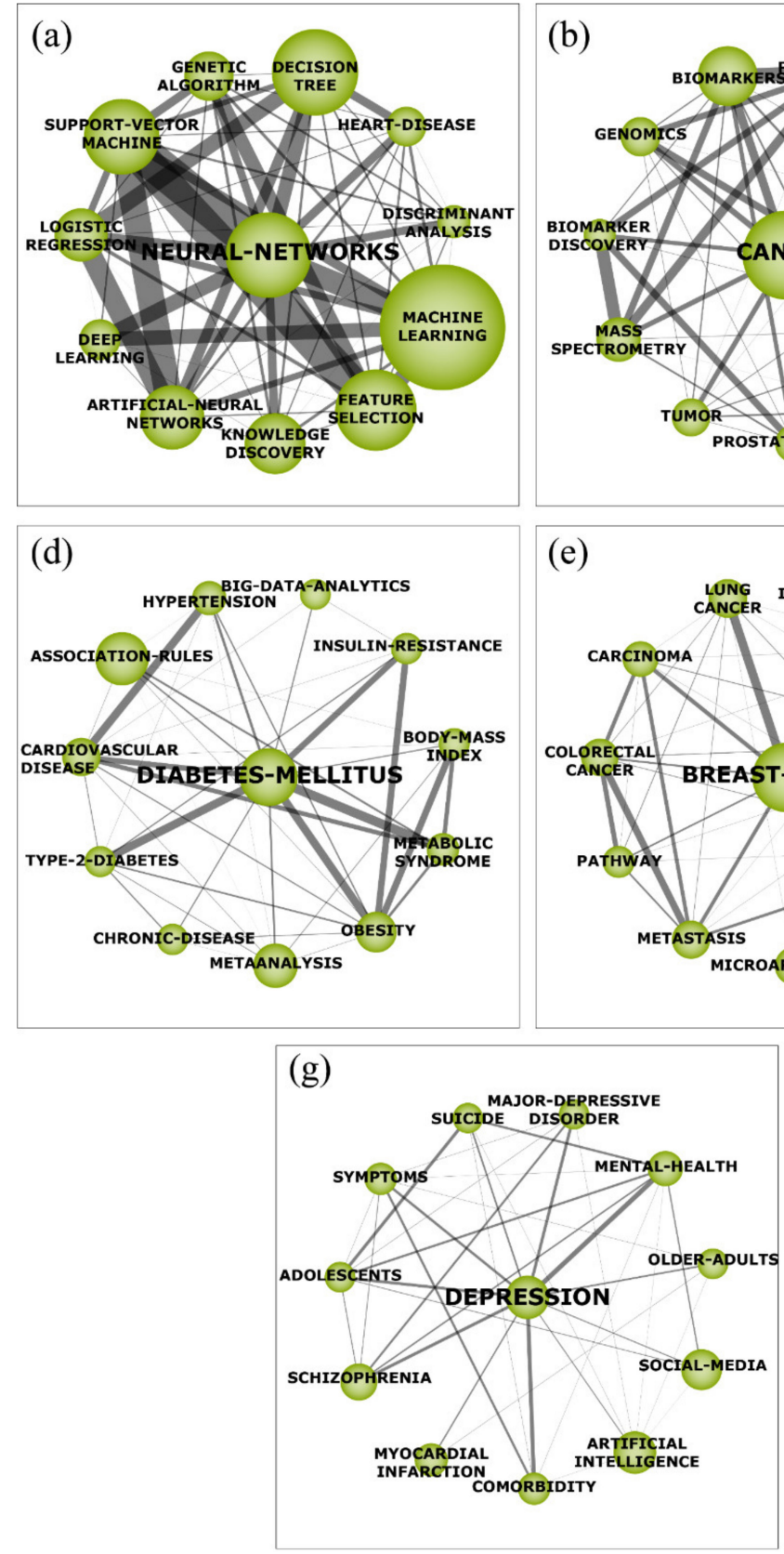

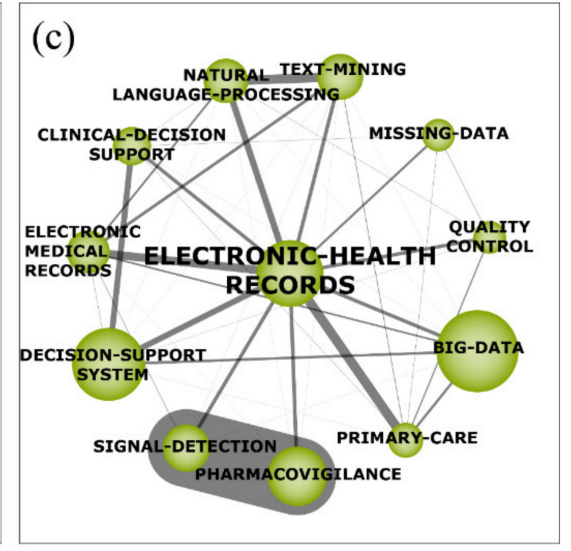

(e)
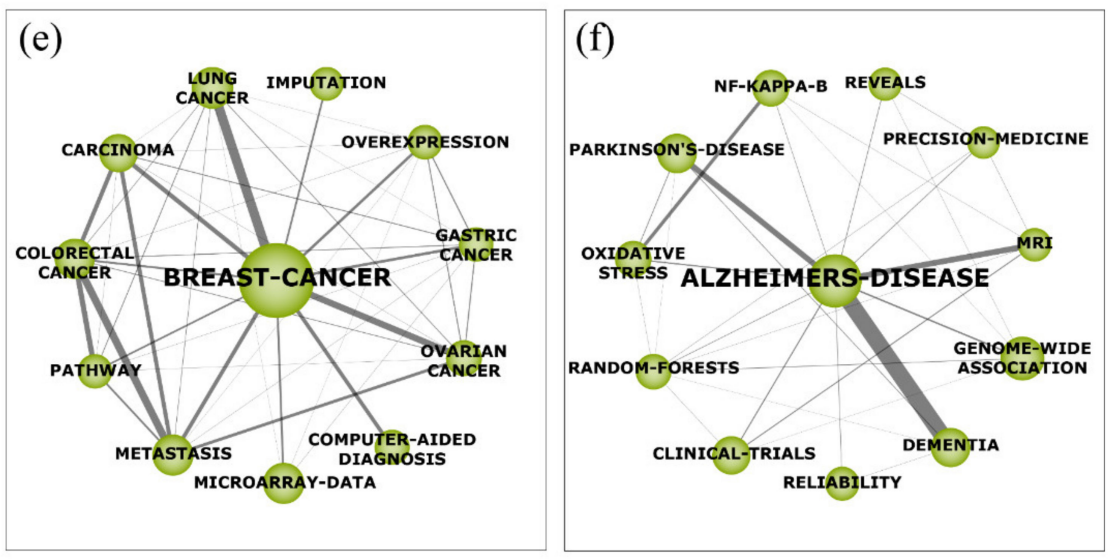

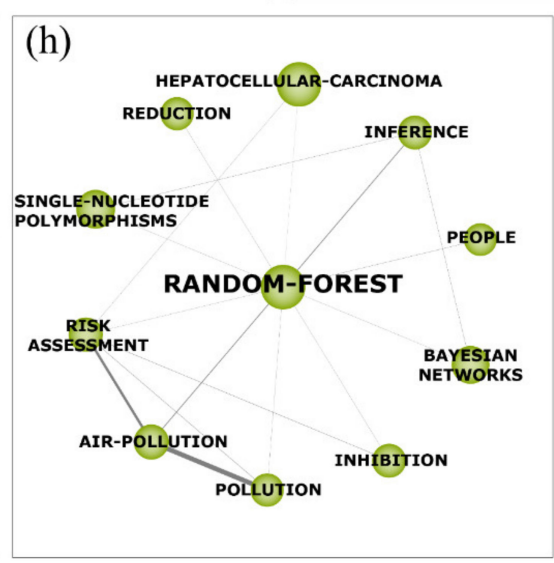

Figure 5. Thematic network structure of mining in healthcare (1995-July 2020). (a) The cluster 'NEURAL-NETWORKS'. (b) The cluster 'CANCER'. (c) The cluster 'ELECTRONIC-HEALTH-RECORDS'. (d) The cluster 'DIABETES-MELLITUS'. (e) The cluster 'BREAST-CANCER'. (f) The cluster 'ALZHEIMER'S DISEASE'. (g) The cluster 'DEPRESSION'. (h) The cluster 'RANDOM-FOREST'.

\subsubsection{Cancer (b)}

The cluster 'CANCER' (Figure 5b) is the second ranked in terms of core documents, hindex, and density. On the other hand, it is the first in terms of citations (5810). This cluster is highly influenced by the subthemes related to the studies of cancer genes mutations, such as 'BIOMAKERS', 'GENE-EXPRESSION', among others. The use of data mining techniques has been attracting attention and efforts from academics in order to help solve problems in the field of oncology. Cancer is known as the disease that kills the most people in the 21st century due to various environmental pollutions, food pesticides and additives [14], eating habits, mental health, among others. Thus, controlling any form of cancer is a global strategy and can be enhanced by applying data mining techniques. 
Furthermore, the subtheme 'PROSTATE-CANCER' highlights that the most efforts of data mining applications focused on prostate cancer's studies. Prostate cancer is the most common cancer in men. Although the benefits of traditional clinical exams for screening (digital rectal examination, the prostate-specific antigen and blood test and transrectal ultrasound), there is still a lack in terms of efficacy to reduce mortality with the use of such tests [43]. In this sense, data mining may be a suitable solution since it has been used in bioinformatics analyses to understand prostate cancer mutation $[44,45]$ and uncover useful information that can be used for diagnoses and future prognostic tests which enhance both patients and clinical decision-making [46].

\subsubsection{Electronic Health Records $(\mathrm{HER}-\mathrm{c})$}

The cluster 'ELECTRONIC-HEALTH-RECORDS' (Figure 5c) represents the concept in which patient's health data are stored. Such data are continuously increasing over time, thereby creating a large amount of data (big data) which has been used as input (EHR) for healthcare decision support systems to enhance clinical decision-making. The clusters 'NATURAL-LANGUAGE-PROCESSING' and 'TEXT MINING' highlight that these mining techniques are the most frequently used with data mining in healthcare. Another pattern that must be highlighted is the considerable density among the clusters 'SIGNAL-DETECTION' and 'PHARMACOVIGILANCE' which represents the use of data mining to depict a broad range of adverse drug effects and to identify signals almost in real-time by using EHR [47,48]. Besides, the cluster 'MISSING-DATA' is related to studies focused on the challenge regarding to incomplete EHR and missing data in healthcare centers, which compromise the performance of several prediction models [49]. In this sense, techniques to handle missing data have been under improvement in order to move forward with the accurate prediction based on medical data mining applications [50].

\subsubsection{Diabetes Mellitus (DM-d)}

Nowadays, DM is one of the most frequent endocrine disorders [51] and affected more than 450 million people worldwide in 2017 and is expected to grow to 693 million by the year 2045. The same applies for the 850 billion dollars spent just in 2017 by the health sector [52]. The cluster 'DIABETES-MELLITUS' (Figure 5d) has a strong association with the risk factor subtheme group (e.g., 'INSULIN-RESISTENCE', 'OBESITY', 'BODY-MASSINDEX', 'CARDIOVASCULAR-DISEASE', and 'HYPERTENSION'). However, the obesity (cluster 'OBESITY') is the major risk factor related to DM, particularly in Type 2 Diabetes (T2D) [51]. T2D shows a prevalence of $90 \%$ of worldwide diabetic patients when compared with T1D and T3D, mainly characterized by insulin resistance [51]. Thus, this might justify the presence of the clusters 'TYPE-2-DIABETES' and 'INSULIN-RESISTANCE' which seems to be highly developed by data mining academics and practitioners. The massive number of researches into all facets of DM has led to the formation of huge volumes of $\mathrm{EHR}$, in which the mostly applied data mining technique is the association rules technique. It is used to identify associations among risk factors [51], thusly justifying the appearance of the cluster 'ASSOCIATION-RULES'.

\subsubsection{Breast Cancer (e)}

The cluster 'BREAST-CANCER' (Figure 5e) presents the most prevalent type of cancer affecting approximately $12.5 \%$ of women worldwide $[53,54]$. The cluster 'OVEREXPRESSION' and 'METASTASIS' highlights the high number of studies using data mining to understand the association of overexpression of molecules (e.g., MUC1 [54], TRIM29 [55], FKBP4 [56], etc.) with breast cancer metastasis. Such overexpression of molecules also appears in other forms of cancers, justifying the group of subthemes: 'LUNG CANCER', 'GASTRIC-CANCER', 'OVARIAN-CANCER', and 'COLORECTALCANCER'. Moreover, the cluster 'IMPUTATION' highlight efforts to develop imputation techniques (data missingness) for breast cancer record analysis [57,58]. Besides, the application of data mining to depict breast cancer characteristics and their causes and effects has been highly sup- 
ported by 'MICROARRAY-DATA' [59,60], 'PATHWAY' [61], and 'COMPUTER-AIDEDDIAGNOSIS' [62].

\subsubsection{Alzheimer's Disease (AD—f)}

The cluster 'ALZHEIMER'S DISEASE' (Figure $5 f$ ) is highly influenced by subthemes related to diseases, such as 'DEMENTIA' and 'PARKINSON'S-DISEASE'. This co-occurrence happens because the $\mathrm{AD}$ is a neurodegenerative illness which leads to dementia and Parkinson's disease. Studies show that the money spent on AD in 2015 was about $\$ 828$ billion [63]. In this sense, data mining has been widely used with 'GENOME-WIDE-ASSOCIATION' techniques in order to identify genes related to the $\mathrm{AD}[64,65]$ and prediction of $\mathrm{AD}$ by using data mining in 'MRI' Brain images [66,67]. The cluster 'NF-KAPPA-B' highlights the efforts to identify associations of NF- $\mathrm{KB}$ (factor nuclear kappa B) with AD by using data mining techniques which can be used to advance anti-drug developments [68].

\subsubsection{Depression (g)}

The cluster 'DEPRESSION' (Figure 5g) presents a common disease which affects over 260 million people. In the worst case, it can lead to suicide which is the second leading cause of death in young adults. The cluster 'DEPRESSION' is a highly associated cluster. Its connections mostly represent the subthemes that have been the research focus of data mining applications [69]. The connection between both the sub theme 'SOCIAL-MEDIA' and 'ADOLESCENTS', especially in times of social isolation, are extremely relevant to help identify early symptoms and tendencies among the population [70]. Furthermore, the presence of the 'COMORBIDITY' and 'SYMPTONS' is not surprising given knowledge discovery properties of the data mining field could provide significant insights into the etiology of depression [71].

\subsubsection{Random Forest (h)}

An ensemble learning method that is used in this study is the last cluster approach, which, among other things, is used for classification. The presence of the 'BAYESIANNETWORK' subtheme, supported by the connection between both and the 'INFERENCE', might represent another alternative to which the applications in data mining using random forest are benchmarked against [72]. Since the 'RANDOM-FOREST' (Figure 5h) cluster has barely passed the threshold from a basic and transversal theme to a motor theme, the works developed under this cluster are not yet as interconnected as the previous one. Thus, the theme with the most representativeness is the 'AIR-POLLUTION' in conjunction with 'POLLUTION', where studies have been performed in order to obtain 'RISK-ASSESSMENT' through the exploration of the knowledge hidden in large databases [73].

\subsection{Thematic Evolution Structure Analysis}

The Computer Science's themes related to data mining and the medical research concepts, depicted, respectively, in the grey and blue areas of the thematic evolution diagram (Figure 6), demonstrates the evolution of the research field over the different subperiods addressed in this study. In this way, each individual theme relevance is illustrated through its cluster size as well as with its relationships throughout the different sub-periods. Thus, in this section, an analysis of the different trends on themes will be presented to give a brief insight into the factors that might have influenced its evolution. Furthermore, the proceeding analysis will be split into two thematic areas where, firstly, the grey area (practices and techniques related to data mining in healthcare) will be discussed followed by the blue one (health concepts and disease supported by data mining). 


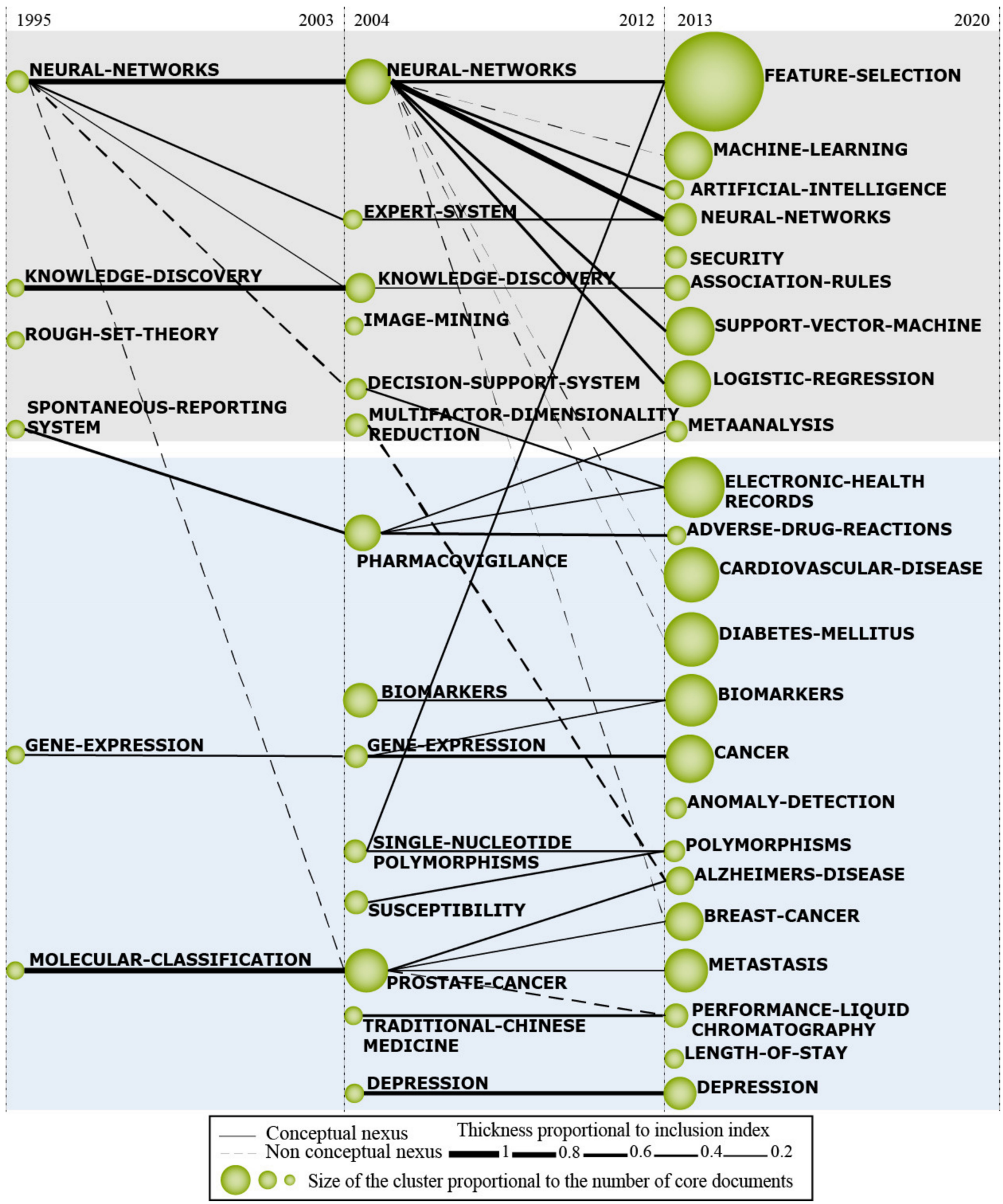

Figure 6. Thematic evolution structure of mining in healthcare (1995-July 2020).

\subsubsection{Practices and Techniques Related to Data Mining in Healthcare}

The cluster 'KNOWLEDGE-DISCOVERY' (Figure 6, 1995-2012), often known as a synonym for data mining, provides a broader view of the field differing in this way from the algorithm focused theme, that is data mining, where its appearance and, later in the third period, its fading could provide a first insight into the overall evolution of the data mining papers applied to healthcare. The occurrence of the cluster knowledge discovery in the first two periods could demonstrate the focus of the application of the data mining techniques in order to classify and predict conditions in the medical field. This gives rise to a competition 
with early machine learning techniques that could be potentially evidenced through the presence of the cluster 'NEURAL-NETWORK', which the data mining techniques could probably be benchmarked against. The introduction of the 'FEATURE-SELECTION', 'ARTIFICIAL-INTELLIGENCE', and 'MACHINE-LEARNING' clusters together with the fading of 'KNOWLEDGE-DISCOVERY' could imply the occurrence of a disruption of the field in the third sub-period that has led to a change in the perspective on the studies.

One instance that could represent such a disruption could have been a well-known paper published by Alex Krizhevsky, Ilya Sutskever, and Geoffrey Hinton [74], where a novel technique in neural networks was firstly applied to a major image recognition competition. A vast advantage over the other algorithms that have been used was obtained. The connection between the work previously mentioned and its impact on the data mining on healthcare research could be majorly supported by the disappearance of the cluster 'IMAGE- MINING' of the second sub-period which has no connections further on. Furthermore, the presence of the clusters 'MACHINE-LEARNING', 'ARTIFICIALINTELLIGENCE', 'SUPPORT-VECTOR-MACHINES', and 'LOGISTIC-REGRESSION' may be the evidence of a shift of focus on the data mining community for health care where, besides attempting to compete with machine learning algorithms, they are now striving to further improve the results previously obtained with machine learning through data mining. Moreover, given the presence of the colossal feature selection cluster, which circumscribes algorithms that enhance classification accuracy through a better selection of parameters, this trend could be given credence in consequence of its presence since it may be encompassing publications from the formerly stated clusters.

Although still small, the presence of the cluster 'SECURITY' in the last sub-period (Figure 6, 2013-2020) is, at the very least, relevant given the sensitive data that is handled in the medical space, such as patient's history and diseases. Above all, the recent leaks of personal information have devised an ever-increasing attention to this topic focusing on, among other things, the de-identification of the personal information [75-77]. These kind of security processes allow, among others, data mining researchers to make use of the vast sensitive information that is stored in hospitals without any linkage that could associate a person to the data. For instance, the MIMIC Critical Care Database [78], an example of a de-identified database, has been allowing further research into many diseases and conditions in a secure way that would otherwise have been extremely impaired due to data limitations.

\subsubsection{Health Concepts and Disease Supported by Data Mining}

The cluster 'GENE-EXPRESSION' stands out in the first period and second period (Figure 6, 1995-2012) of medical research concepts and establishes strong co-occurrence with the cluster 'CANCER' in the third sub-period. This link can be explained by research involving the microarray technology, which makes it possible to detect deletions and duplications in the human genome by analyzing the expression of thousands of genes in different tissues. It is also possible to confirm the importance of genetic screening not only for cancer, but for several diseases, such as 'ALZHEIMER' and other brain disorders, thereby assisting in preventive medicine and enabling more efficient treatment plans [79]. For example, a research was carried out to analyze complex brain disorders such as schizophrenia from expression gene microarrays [80].

Sequencing technologies have undergone major improvements in recent decades to determine evolutionary changes in genetic, epigenetic mechanisms, and in the 'MOLECULARCLASSIFICATION', a topic that gained prominence as a cluster in the first period. An example of this can be found in a study published in 2010 which combined a global optimization algorithm called Dongguang Li (DGL) with cancer diagnostic methods based on gene selection and microarray analysis. It performed the molecular classification of colon cancers and leukemia and demonstrated the importance of machine learning, data mining, and good optimization algorithms for analyzing microarray data in the presence of subsets of thousands of genes [81]. 
The cluster 'PROSTATE-CANCER' in the second period (Figure 6, 2004-2012) presents a higher conceptual nexus to 'MOLECULAR-CLASSIFICATION' in the first sub-period and the same happens with clusters, such as 'METASTASIS', 'BREAST-CANCER', and 'ALZHEIMER', which appear more recently in the third sub-period. The significant increase in the incidence of prostate cancer in recent years results in the need for greater understanding of the disease in order to increase patient survival, since prostate cancer with metastasis was not well explored, despite having a survival rate much smaller compared to the early stages. In this sense, the understanding of age-specific survival of patients with prostate cancer in a hospital in using machine learning started to gain attention by academics and highlighted the importance of knowing survival after diagnosis for decision making and better genetic counseling [82]. In addition, the relationship between prostate cancer and Alzheimer's disease is explained by the fact that the use of androgen deprivation therapy, used to treat prostate cancer, is associated with an increased risk of Alzheimer's disease and dementia [81]. Therefore, the risks and benefits of long-term exposure to this therapy must be weighed. Finally, the relationship between prostate cancer and breast cancer in the thematic evolution can be explained due to the fact that studies are showing that men with a family history of breast cancer have a $21 \%$ higher risk of developing prostate cancer, including lethal disease [83].

The cluster 'PHARMACOVIGILANCE' appears in the second sub-period (Figure 6, 2004-2012) showing a strong co-occurrence with clusters of the third sub-period: 'ADVERSEDRUGS-REACTIONS' and 'ELECTRONIC-HEALTH-RECORDS'. In recent years, datamining algorithms have stood out for their usefulness in detecting and screening patients with potential adverse drug reactions and, consequently, they have become a central component of pharmacovigilance, important for reducing the morbidity and mortality associated with the use of medications [48]. The importance of electronic medical records for pharmacovigilance is evident, which act as a health database and enable drug safety assessors to collect information. In addition, such medical records are also essential to optimize processes within health institutions, ensure more safety of patient data, integrate information, and facilitate the promotion of science and research in the health field [84]. These characteristics explain the large number of studies of 'ELECTRONIC-HEALTHRECORDS' in the third sub-period and the growth of this theme in recent years, since the world has started to introduce electronic medical records, although currently there are few institutions that still use physical medical records.

The 'DEPRESSION' appears in the second sub-period (Figure 6, 2004-2012) and remains as a trend in the third sub-period with a significant increase in publications on the topic. It is known that this disease is numerous and is increasing worldwide, but that it still has many stigmas in its treatment and diagnosis. Globalization and the contemporary work environment [85] can be explanatory factors for the increase in the theme from the 2000s onwards and the COVID-19 pandemic certainly contributed to the large number of articles on mental health published in 2020. In this context, improving the detection of mental disorders is essential for global health, which can be enhanced by applying data mining to quantitative electroencephalogram signals to classify between depressed and healthy people and can act as an adjuvant clinical decision support to identify depression [69].

\section{Conclusions}

In this research, we have performed a BPNA to depict the strategic themes, the thematic network structure, and the thematic evolution structure of the data mining applied in healthcare. Our results highlighted several significant pieces of information that can be used by decision-makers to advance the field of data mining in healthcare systems. For instance, our results could be used by editors from scientific journals to enhance decision-making regarding special issues and manuscript review. From the same perspective, healthcare institutions could use this research in the recruiting process to better align the position needs to the candidate's qualifications based on the expanded clusters. Furthermore, Table 2 presents a series of authors whose collaboration network 
may be used as a reference to identify emerging talents in a specific research field and might become persons of interest to greatly expand a healthcare institution's research division. Additionally, Tables 3 and 4 could also be used by researchers to enhance the alignment of their research intentions and partner institutions to, for instance, encourage the development of data mining applications in healthcare and advance the field's knowledge.

The strategic diagram (Figure 4) depicted the most important themes in terms of centrality and density. Such results could be used by researchers to provide insights for a better comprehension of how diseases like 'CANCER', 'DIABETES-MELLITUS', 'ALZHEIMER'SDISEASE', 'BREAST-CANCER', 'DEPRESSION', and 'CORONARY-ARTERY-DISEASE' have made use of the innovations in the data mining field. Interestingly, none of the clusters have highlighted studies related to infectious diseases, and, therefore, it is reasonable to suggest the exploration of data mining techniques in this domain, especially given the global impact that the coronavirus pandemic has had on the world.

The thematic network structure (Figure 5) demonstrates the co-occurrences among clusters and may be used to identify hidden patterns in the field of research to expand the knowledge and promote the development of scientific insights. Even though exhaustive research of the motor themes and their subthemes has been performed in this article, future research must be conducted in order to depict themes from the other quadrants $(\mathrm{Q} 2, \mathrm{Q} 3$, and Q4), especially emerging and declining themes, to bring to light relations between the rise and decay of themes that might be hidden inside the clusters.

The thematic evolution structure showed how the field is evolving over time and presented future trends of data mining in healthcare. It is reasonable to predict that clusters such as 'NEURAL-NETWORKS', 'FEATURE-SELECTION', 'EHR' will not decay in the near future due to their prevalence in the field and, most likely, due to the exponential increase in the amount of patient health that is being generated and stored daily in large data lakes. This unprecedented increase in data volume, which is often of dubious quality, leads to great challenges in the search for hidden information through data mining. Moreover, as a consequence of the ever-increasing data sensitivity, the cluster 'SECURITY', which is related to the confidentiality of the patient's information, is likely to remain growing during the next years as government and institutions further develop structures, algorithms, and laws that aim to assure the data's security. In this context, blockchain technologies specifically designed to ensure integrity and publicity of de-identified, similarly as it is done by the MIMIC-III (Medical Information Mart for Intensive Care III) [78], may be crucial to accelerate the advancement of the field by providing reliable information for health researchers across the world. Furthermore, future researches should be conducted in order to understand how these themes will behave and evolve during the next years, and interpret the cluster changes to properly assess the trends here presented. These results could also be used as teaching material for classes, as it provides strategic intelligence applications and the field's historical data.

In terms of limitations, we used the WoS database since it has index journals with high JIF. Therefore, we suggest to analyze other databases, such as Scopus, PubMed, among others in future works. Besides, we used the SciMAT to perform the analysis and other bibliometric software, such as VOS viewer, Cite Space, Sci2tool, etc., could be used to explore different points of view. Such information will support this study and future works to advance the field of data mining in healthcare.

Author Contributions: Conceptualization, M.L.K., L.B.F., L.P.C.T. and N.L.B.; Data curation, L.B.F.; Formal analysis, L.B.F., B.R., and P.H.U.; Funding acquisition, N.L.B.; Investigation, M.L.K., L.B.F., L.P.C.T. and M.K.S.; Methodology, L.B.F.; Project administration, L.B.F., N.L.B. and L.P.C.T.; Resources, N.L.B.; Supervision, L.B.F., N.L.B. and L.P.C.T.; Validation, N.L.B. and L.P.C.T.; Visualization, N.L.B.; Writing-original draft, L.B.F. and N.L.B.; Writing-review \& editing, N.L.B. All authors have read and agreed to the published version of the manuscript. 
Funding: This study was financed in part by the Coordenação de Aperfeiçoamento de Pessoal de Nivel Superior-Brazil (CAPES) —Finance Code 001, and in part by the Brazilian Ministry of Health. N.L.B. is partially supported by the CIHR 2019 Novel Coronavirus (COVID-19) rapid research program.

Institutional Review Board Statement: Not applicable.

Informed Consent Statement: Not applicable.

Data Availability Statement: Not applicable.

Conflicts of Interest: The authors declare no conflict of interest.

\section{References}

1. Jayaraman, P.P.; Forkan, A.R.M.; Morshed, A.; Haghighi, P.D.; Kang, Y. Healthcare 4.0: A Review of Frontiers in Digital Health. In Wiley Interdisciplinary Reviews: Data Mining and Knowledge Discovery; Wiley: Hoboken, NJ, USA, 2020; Volume 10, p. e1350. [CrossRef]

2. Jothi, N.; Husain, W. Data mining in healthcare-A review. Procedia Comput. Sci. 2015, 72, 306-313. [CrossRef]

3. Ricciardi, C.; Cantoni, V.; Improta, G.; Iuppariello, L.; Latessa, I.; Cesarelli, M.; Triassi, M.; Cuocolo, A. Application of data mining in a cohort of Italian subjects undergoing myocardial perfusion imaging at an academic medical center. Comput. Methods Programs Biomed. 2020, 189, 105343. [CrossRef] [PubMed]

4. Pika, A.; Wynn, M.T.; Budiono, S.; Ter Hofstede, A.H.; van der Aalst, W.M.; Reijers, H.A. Privacy-Preserving Process Mining in Healthcare. Int. J. Environ. Res. Public Health 2020, 17, 1612. [CrossRef]

5. Ricciardi, C.; Amboni, M.; de Santis, C.; Improta, G.; Volpe, G.; Iuppariello, L.; Ricciardelli, G.; D’Addio, G.; Vitale, C.; Barone, P.; et al. Using gait analysis' parameters to classify Parkinsonism: A data mining approach. Comput. Methods Programs Biomed. 2019, 180, 105033. [CrossRef] [PubMed]

6. Ayyoubzadeh, S.M.; Ghazisaeedi, M.; Kalhori, S.R.N.; Hassaniazad, M.; Baniasadi, T.; Maghooli, K.; Kahnouji, K. A study of factors related to patients' length of stay using data mining techniques in a general hospital in southern Iran. Health Inf. Sci. Syst. 2020, 8, 9. [CrossRef]

7. Huang, C.; Xu, X.; Cai, Y.; Ge, Q.; Zeng, G.; Li, X.; Zhang, W.; Ji, C.; Yang, L. Mining the Characteristics of COVID-19 Patients in China: Analysis of Social Media Posts. J. Med. Internet Res. 2020, 22, e19087. [CrossRef]

8. Yim, S.J.; Lui, L.M.; Lee, Y.; Rosenblat, J.D.; Ragguett, R.-M.; Park, C.; Subramaniapillai, M.; Cao, B.; Zhou, A.; Rong, C.; et al. The utility of smartphone-based, ecological momentary assessment for depressive symptoms. J. Affect. Disord. 2020, 274, 602-609. [CrossRef]

9. Uba, M.M.; Jiadong, R.; Sohail, M.N.; Irshad, M.; Yu, K. Data mining process for predicting diabetes mellitus based model about other chronic diseases: A case study of the northwestern part of Nigeria. Healthc. Technol. Lett. 2019, 6, 98-102. [CrossRef] [PubMed]

10. Chen, S.-I.; Tseng, H.-T.; Hsieh, C.-C. Evaluating the impact of soy compounds on breast cancer using the data mining approach. Food Funct. 2020, 11, 4561-4570. [CrossRef] [PubMed]

11. Rahman, A.; Honan, B.; Glanville, T.; Hough, P.; Walker, K. Using data mining to predict emergency department length of stay greater than 4 hours: Derivation and single-site validation of a decision tree algorithm. Emerg. Med. Australas. 2019, 32, 416-421. [CrossRef]

12. Ahmad, P.; Qamar, S.; Rizvi, S.Q.A. Techniques of Data Mining In Healthcare: A Review. Int. J. Comput. Appl. 2015, 120, 38-50. [CrossRef]

13. Țăranu, I. Data mining in healthcare: Decision making and precision. Database Syst. J. 2016, 6, 33-40.

14. Wang, X.; Guo, J.; Gu, D.; Yang, Y.; Yang, X.; Zhu, K. Tracking knowledge evolution, hotspots and future directions of emerging technologies in cancers research: A bibliometrics review. J. Cancer 2019, 10, 2643-2653. [CrossRef]

15. dos Santos, B.S.; Steiner, M.T.A.; Fenerich, A.T.; Lima, R.H.P. Data mining and machine learning techniques applied to public health problems: A bibliometric analysis from 2009 to 2018. Comput. Ind. Eng. 2019, 138, 106120. [CrossRef]

16. Hu, Y.; Yu, Z.; Cheng, X.; Luo, Y.; Wen, C. A bibliometric analysis and visualization of medical data mining research. Medicine 2020, 99, e20338. [CrossRef] [PubMed]

17. Severo, P.; Furstenau, L.; Sott, M.; Cossul, D.; Bender, M.; Bragazzi, N. Thirty Years of Human Rights Study in the Web of Science Database (1990-2020). Int. J. Environ. Res. Public Health 2021, 18, 2131. [CrossRef] [PubMed]

18. Cobo, M.J.; López-Herrera, A.G.; Herrera-Viedma, E.; Herrera, F. SciMAT: A new science mapping analysis software tool. J. Am. Soc. Inf. Sci. Technol. 2012, 63, 1609-1630. [CrossRef]

19. Sott, M.; Bender, M.S.; Furstenau, L.B.; Machado, L.M.; Cobo, M.J.; Bragazzi, N.L. 100 Years of Scientific Evolution of Work and Organizational Psychology: A Bibliometric Network Analysis From 1919 to 2019. Front. Psychol. 2020, 11, 559. [CrossRef] [PubMed]

20. Furstenau, L.B.; Sott, M.K.; Homrich, A.J.O.; Kipper, L.M.; Al Abri, A.A.; Cardoso, T.F.; López-Robles, J.R.; Cobo, M.J. 20 Years of Scientific Evolution of Cyber Security: A Science Mapping. In Proceedings of the International Conference on Industrial Engineering and Operations Management, Dubai, UAE, 10-12 March 2020. 
21. Furstenau, L.B.; Sott, M.; Kipper, L.M.; Machado, E.L.; Lopez-Robles, J.R.; Dohan, M.S.; Cobo, M.J.; Zahid, A.; Abbasi, Q.H.; Imran, M.A. Link Between Sustainability and Industry 4.0: Trends, Challenges and New Perspectives. IEEE Access 2020, 8 140079-140096. [CrossRef]

22. Sott, M.; Furstenau, L.B.; Kipper, L.M.; Giraldo, F.D.; Lopez-Robles, J.R.; Cobo, M.J.; Zahid, A.; Abbasi, Q.H.; Imran, M.A. Precision Techniques and Agriculture 4.0 Technologies to Promote Sustainability in the Coffee Sector: State of the Art, Challenges and Future Trends. IEEE Access 2020, 8, 149854-149867. [CrossRef]

23. López-Robles, J.R.; Otegi-Olaso, J.R.; Cobo, M.J.; Bertolin-Furstenau, L.; Kremer-Sott, M.; López-Robles, L.D.; Gamboa-Rosales, N.K. The relationship between Project Management and Industry 4.0: Bibliometric Analysis of Main Research Areas through Scopus. In Proceedings of the 3rd International Conference on Research and Education in Project Management-REPM 2020, Bilbao, Spain, 20-21 February 2020; p. 56.

24. Kipper, L.M.; Iepsen, S.; Forno, A.J.D.; Frozza, R.; Furstenau, L.; Agnes, J.; Cossul, D. Scientific mapping to identify competencies required by industry 4.0. Technol. Soc. 2021, 64, 101454. [CrossRef]

25. Kipper, L.M.; Furstenau, L.B.; Hoppe, D.; Frozza, R.; Iepsen, S. Scopus scientific mapping production in industry 4.0 (2011-2018): A bibliometric analysis. Int. J. Prod. Res. 2019, 58, 1605-1627. [CrossRef]

26. Furstenau, L.; Rabaioli, B.; Sott, M.; Cossul, D.; Bender, M.; Farina, E.; Filho, F.; Severo, P.; Dohan, M.; Bragazzi, N. A Bibliometric Network Analysis of Coronavirus during the First Eight Months of COVID-19 in 2020. Int. J. Environ. Res. Public Health 2021, 18, 952. [CrossRef]

27. Furstenau, L.B.; Sott, M.K.; Homrich, A.J.O.; Kipper, L.M.; Dohan, M.S.; López-Robles, J.R.; Cobo, M.J.; Tortorella, G.L. An overview of 42 years of lean production: Applying bibliometric analysis to investigate strategic themes and scientific evolution structure. Technol. Anal. Strateg. Manag. 2021, 33, 1-20. [CrossRef]

28. Callon, M.; Courtial, J.P.; Laville, F. Co-word analysis as a tool for describing the network of interactions between basic and technological research: The case of polymer chemsitry. Scientometrics 1991, 22, 155-205. [CrossRef]

29. Viedma, E.H.; Robles, J.R.L.; Guallar, J.; Cobo, M.J. Global trends in coronavirus research at the time of Covid-19: A general bibliometric approach and content analysis using SciMAT. Inf. Prof. 2020, 29, 11.

30. Cobo, M.J.; López-Herrera, A.G.; Herrera-Viedma, E.; Herrera, F. Science mapping software tools: Review, analysis, and cooperative study among tools. J. Am. Soc. Inf. Sci. Technol. 2011, 62, 1382-1402. [CrossRef]

31. Cobo, M.J.; Martínez, M.Á.; Gutiérrez-Salcedo, M.; Fujita, H.; Herrera-Viedma, E. 25 years at Knowledge-based systems: A bibliometric analysis. Knowl. Based Syst. 2015, 80, 3-13. [CrossRef]

32. López-Robles, J.R.; Otegi-Olaso, J.R.; Gómez, I.P.; Cobo, M.J. 30 years of intelligence models in management and business: A bibliometric review. Int. J. Inf. Manag. 2019, 48, 22-38. [CrossRef]

33. Silva, A.L.E.; Moraes, J.A.R.; Benitez, L.B.; Kaufmann, E.A.; Furstenau, L.B. Mapeamento da produção científica acerca do uso de biocompósitos nos processos de impressões 3D. Ibero Am. J. Environ. Sci. 2020, 11, 236-250. [CrossRef]

34. López-Robles, J.R.; Otegi-Olaso, J.R.; Porto-Gomez, I.; Gamboa-Rosales, H.; Gamboa-Rosales, N.K. Understanding the intellectual structure and evolution of Competitive Intelligence: A bibliometric analysis from 1984 to 2017. Technol. Anal. Strateg. Manag. 2019, 32, 604-619. [CrossRef]

35. Cobo, M.J.; López-Herrera, A.G.; Herrera-Viedma, E.; Herrera, F. An approach for detecting, quantifying, and visualizing the evolution of a research field: A practical application to the fuzzy sets theory field. J. Informetr. 2011, 5, 146-166. [CrossRef]

36. Szolovits, P. Uncertainty and decisions in medical informatics. Methods Inf. Med. 1995, 34, 111-121. [CrossRef] [PubMed]

37. Fawcett, T. An introduction to ROC analysis. Pattern Recognit. Lett. 2006, 27, 861-874. [CrossRef]

38. Dohan, M.S.; Califf, C.B.; Ghosh, K.; Tan, J. Digital Transformation in Healthcare: New Value for a New Movement; Elsevier: Amsterdam, The Netherlands, 2020.

39. Wang, J. Citation time window choice for research impact evaluation. Scientometrics 2013, 94, 851-872. [CrossRef]

40. Eyal-Altman, N.; Last, M.; Rubin, E. PCM-SABRE: A platform for benchmarking and comparing outcome prediction methods in precision cancer medicine. BMC Bioinform. 2017, 18, 1-7. [CrossRef] [PubMed]

41. Urbanowicz, R.J.; Olson, R.S.; Schmitt, P.; Meeker, M.; Moore, J.H. Benchmarking relief-based feature selection methods for bioinformatics data mining. J. Biomed. Inform. 2018, 85, 168-188. [CrossRef]

42. Mansiaux, Y.; Carrat, F. Detection of independent associations in a large epidemiologic dataset: A comparison of random forests, boosted regression trees, conventional and penalized logistic regression for identifying independent factors associated with H1N1pdm influenza infections. BMC Med. Res. Methodol. 2014, 14, 99. [CrossRef]

43. Ilic, D.; Neuberger, M.M.; Djulbegovic, M.; Dahm, P. Screening for prostate cancer. Cochrane Database Syst. Rev. 2013, CD004720. [CrossRef] [PubMed]

44. Torrano, V.; Valcarcel-Jimenez, L.; Cortazar, A.R.; Liu, X.; Urosevic, J.; Castillo-Martin, M.; Fernández-Ruiz, S.; Morciano, G.; Caro-Maldonado, A.; Guiu, M.; et al. The metabolic co-regulator PGC1 $\alpha$ suppresses prostate cancer metastasis. Nat. Cell Biol. 2016, 18, 645-656. [CrossRef] [PubMed]

45. Harder, N.; Athelogou, M.; Hessel, H.; Brieu, N.; Yigitsoy, M.; Zimmermann, J.; Baatz, M.; Buchner, A.; Stief, C.G.; Kirchner, T.; et al. Tissue Phenomics for prognostic biomarker discovery in low- and intermediate-risk prostate cancer. Sci. Rep. 2018, 8, 1-19. [CrossRef]

46. Coates, J.; Souhami, L.; El Naqa, I. Big Data Analytics for Prostate Radiotherapy. Front. Oncol. 2016, 6, 149. [CrossRef] 
47. Trifirò, G.; Pariente, A.; Coloma, P.M.; Kors, J.A.; Polimeni, G.; Miremont-Salamé, G.; Catania, M.A.; Salvo, F.; David, A.; Moore, N.; et al. Data mining on electronic health record databases for signal detection in pharmacovigilance: Which events to monitor? Pharmacoepidemiol. Drug Saf. 2009, 18, 1176-1184. [CrossRef]

48. Harpaz, R.; Vilar, S.; DuMouchel, W.; Salmasian, H.; Haerian, K.; Shah, N.H.; Chase, H.S.; Friedman, C. Combing signals from spontaneous reports and electronic health records for detection of adverse drug reactions. J. Am. Med. Inform. Assoc. 2013, 20, 413-419. [CrossRef]

49. Stiglic, G.; Kocbek, P.; Fijacko, N.; Sheikh, A.; Pajnkihar, M. Challenges associated with missing data in electronic health records: A case study of a risk prediction model for diabetes using data from Slovenian primary care. Health Inform. J. 2017, 25, 951-959. [CrossRef]

50. Purwar, A.; Singh, S.K. Hybrid prediction model with missing value imputation for medical data. Expert Syst. Appl. 2015, 42, 5621-5631. [CrossRef]

51. Kavakiotis, I.; Tsave, O.; Salifoglou, A.; Maglaveras, N.; Vlahavas, I.; Chouvarda, I. Machine Learning and Data Mining Methods in Diabetes Research. Comput. Struct. Biotechnol. J. 2017, 15, 104-116. [CrossRef]

52. Cho, N.; Shaw, J.; Karuranga, S.; Huang, Y.; Fernandes, J.D.R.; Ohlrogge, A.; Malanda, B. IDF Diabetes Atlas: Global estimates of diabetes prevalence for 2017 and projections for 2045. Diabetes Res. Clin. Pract. 2018, 138, 271-281. [CrossRef] [PubMed]

53. García-Laencina, P.J.; Abreu, P.H.; Abreu, M.H.; Afonoso, N. Missing data imputation on the 5-year survival prediction of breast cancer patients with unknown discrete values. Comput. Biol. Med. 2015, 59, 125-133. [CrossRef] [PubMed]

54. Oskouei, R.J.; Kor, N.M.; Maleki, S.A. Data mining and medical world: Breast cancers' diagnosis, treatment, prognosis and challenges. Am. J. Cancer Res. 2017, 7, 610-627. [PubMed]

55. Zadeh, A.H.; Alsabi, Q.; Ramirez-Vick, J.E.; Nosoudi, N. Characterizing basal-like triple negative breast cancer using gene expression analysis: A data mining approach. Expert Syst. Appl. 2020, 148, 113253. [CrossRef]

56. Xiong, H.; Chen, Z.; Zheng, W.; Sun, J.; Fu, Q.; Teng, R.; Chen, J.; Xie, S.; Wang, L.; Yu, X.-F.; et al. FKBP4 is a malignant indicator in luminal A subtype of breast cancer. J. Cancer 2020, 11, 1727-1736. [CrossRef]

57. Wu, X.; Khorshidi, H.A.; Aickelin, U.; Edib, Z.; Peate, M. Imputation techniques on missing values in breast cancer treatment and fertility data. Health Inf. Sci. Syst. 2019, 7, 1-8. [CrossRef]

58. Nekouie, A.; Moattar, M.H. Missing value imputation for breast cancer diagnosis data using tensor factorization improved by enhanced reduced adaptive particle swarm optimization. J. King Saud Univ. Comput. Inf. Sci. 2019, 31, 287-294. [CrossRef]

59. Kassim, S.K.; Shehata, H.H.; Abou-Alhussein, M.M.; Sallam, M.M.; Amin, I.I. Laboratory validation of formal concept analysis of the methylation status of microarray-detected genes in primary breast cancer. Tumor Biol. 2017, 39, 1010428317698390. [CrossRef] [PubMed]

60. Chou, H.-L.; Yao, C.-T.; Su, S.-L.; Lee, C.-Y.; Hu, K.-Y.; Terng, H.-J.; Shih, Y.-W.; Chang, Y.-T.; Lu, Y.-F.; Chang, C.-W.; et al. Gene expression profiling of breast cancer survivability by pooled cDNA microarray analysis using logistic regression, artificial neural networks and decision trees. BMC Bioinform. 2013, 14, 100. [CrossRef]

61. Maind, A.; Raut, S. Identifying condition specific key genes from basal-like breast cancer gene expression data. Comput. Biol. Chem. 2019, 78, 367-374. [CrossRef]

62. Valarmathie, P.; Sivakrithika, V.; Dinakaran, K. Classification of mammogram masses using selected texture, shape and margin features with multilayer perceptron classifier. Biomed. Res. 2016, 27, S310.

63. Tsutsui, S.; Bu, Y.; Ding, Y. Using Machine Reading to Understand Alzheimer's and Related Diseases from the Literature. J. Data Inf. Sci. 2017, 2, 81-94. [CrossRef]

64. Walker, P.R.; Smith, B.; Liu, Q.Y.; Famili, A.F.; Valdés, J.J.; Liu, Z.; Lach, B. Data mining of gene expression changes in Alzheimer brain. Artif. Intell. Med. 2004, 31, 137-154. [CrossRef]

65. Colangelo, V.; Schurr, J.; Ball, M.J.; Pelaez, R.P.; Bazan, N.G.; Lukiw, W.J. Gene expression profiling of 12633 genes in Alzheimer hippocampal CA1: Transcription and neurotrophic factor down-regulation and up-regulation of apoptotic and pro-inflammatory signaling. J. Neurosci. Res. 2002, 70, 462-473. [CrossRef]

66. Lazli, L.; Boukadoum, M.; Mohamed, O.A. A Survey on Computer-Aided Diagnosis of Brain Disorders through MRI Based on Machine Learning and Data Mining Methodologies with an Emphasis on Alzheimer Disease Diagnosis and the Contribution of the Multimodal Fusion. Appl. Sci. 2020, 10, 1894. [CrossRef]

67. Plant, C.; Teipel, S.J.; Oswald, A.; Böhm, C.; Meindl, T.; Mourao-Miranda, J.; Bokde, A.W.; Hampel, H.; Ewers, M. Automated detection of brain atrophy patterns based on MRI for the prediction of Alzheimer's disease. NeuroImage 2010, 50, 162-174 [CrossRef] [PubMed]

68. Zhang, M.; Schmitt-Ulms, G.; Sato, C.; Xi, Z.; Zhang, Y.; Zhou, Y.; George-Hyslop, P.S.; Rogaeva, E. Drug Repositioning for Alzheimer's Disease Based on Systematic 'omics' Data Mining. PLoS ONE 2016, 11, e0168812. [CrossRef] [PubMed]

69. Mohammadi, M.; Al-Azab, F.; Raahemi, B.; Richards, G.; Jaworska, N.; Smith, D.; de La Salle, S.; Blier, P.; Knott, V. Data mining EEG signals in depression for their diagnostic value. BMC Med. Inform. Decis. Mak. 2015, 15, 108. [CrossRef] [PubMed]

70. Kautzky, A.; Baldinger-Melich, P.; Kranz, G.S.; Vanicek, T.; Souery, D.; Montgomery, S.; Mendlewicz, J.; Zohar, J.; Serretti, A.; Lanzenberger, R.; et al. A New Prediction Model for Evaluating Treatment-Resistant Depression. J. Clin. Psychiatry 2017, 78, 215-222. [CrossRef] 
71. Zimmerman, M.; Balling, C.; Chelminski, I.; Dalrymple, K. Symptom presence versus symptom intensity in understanding the severity of depression: Implications for documentation in electronic medical records. J. Affect. Disord. 2019, 256, 344-347. [CrossRef]

72. Chen, Y.; Cao, W.; Gao, X.; Ong, H.; Ji, T. Predicting postoperative complications of head and neck squamous cell carcinoma in elderly patients using random forest algorithm model. BMC Med. Inform. Decis. Mak. 2015, 15, 44. [CrossRef]

73. Kaur, P.; Kumar, R.; Kumar, M. A healthcare monitoring system using random forest and internet of things (IoT). Multimed. Tools Appl. 2019, 78, 19905-19916. [CrossRef]

74. Krizhevsky, A.; Sutskever, I.; Hinton, G.E. Imagenet classification with deep convolutional neural networks. Adv. Neural Inf. Process. Syst. 2012, 25, 1097-1105. [CrossRef]

75. Patil, H.K.; Seshadri, R. Big Data Security and Privacy Issues in Healthcare; IEEE: New York, NY, USA, $2014 ;$ pp. $762-765$.

76. Rajput, A.; Li, Q.; Ahvanooey, M. A Blockchain-Based Secret-Data Sharing Framework for Personal Health Records in Emergency Condition. Healthcare 2021, 9, 206. [CrossRef]

77. Abouelmehdi, K.; Beni-Hessane, A.; Khaloufi, H. Big healthcare data: Preserving security and privacy. J. Big Data $2018,5,1$. [CrossRef]

78. Johnson, A.E.W.; Pollard, T.J.; Shen, L.; Lehman, L.-W.H.; Feng, M.; Ghassemi, M.; Moody, B.; Szolovits, P.; Anthony Celi, L.; Mark, R.G. MIMIC-III, a freely accessible critical care database. Sci. Data 2016, 3, 160035. [CrossRef] [PubMed]

79. Li, D. Gene expression studies with DGL global optimization for the molecular classification of cancer. Soft Comput. 2011, 15, 111-129. [CrossRef]

80. Mirnics, K.; Middleton, F.A.; Lewis, D.A.; Levitt, P. Analysis of complex brain disorders with gene expression microarrays: Schizophrenia as a disease of the synapse. Trends Neurosci. 2001, 24, 479-486. [CrossRef]

81. Romero, I.G.; Ruvinsky, I.; Gilad, Y. Comparative studies of gene expression and the evolution of gene regulation. Nat. Rev. Genet. 2012, 13, 505-516. [CrossRef] [PubMed]

82. Doja, M.; Kaur, I.; Ahmad, T. Age-specific survival in prostate cancer using machine learning. Data Technol. Appl. 2020, 54, 215-234. [CrossRef]

83. Barber, L.E.; Gerke, T.; Markt, S.C.; Peisch, S.F.; Wilson, K.M.; Ahearn, T.U.; Giovannucci, E.L.; Parmigiani, G.; Mucci, L.A. Family History of Breast or Prostate Cancer and Prostate Cancer Risk. Clin. Cancer Res. 2018, 24, 5910-5917. [CrossRef] [PubMed]

84. Shivade, C.; Raghavan, P.; Fosler-Lussier, E.; Embi, P.J.; Elhadad, N.; Johnson, S.B.; Lai, A.M. A review of approaches to identifying patient phenotype cohorts using electronic health records. J. Am. Med. Inform. Assoc. 2014, 21, 221-230. [CrossRef]

85. Bhugra, D.; Mastrogianni, A. Globalisation and mental disorders: Overview with relation to depression. Br. J. Psychiatry 2004, 184, 10-20. [CrossRef] [PubMed] 